Eugeniusz Turyk

Marcin Ciepły

Mirosław Pęcherek

Marek Potrzebski

Tadeusz Kuzio

Bogusław Czwórnóg

Agnieszka Żydzik-Białek

Margrit Bormann

Andrzej Jastrzębiowski

\title{
Spawanie laserowe w naprawie napisu ARBEIT MACHT FREI z bramy głównej byłego obozu Auschwitz I
}

\section{Laser welding in repair of the ARBEIT MACHT FREI inscription parts of the former Auschwitz I Camp entrance gate}

\section{Streszczenie}

W artykule przedstawiono zastosowanie spawania laserowego w naprawie napisu ARBEIT MACHT FREI. Obejmowało ono wykonanie ściegów licowych w złączach doczołowych rur scalających konstrukcję napisu, spawanie naprawcze pęknięć w oryginalnych spoinach łączących litery z rurami, napawanie w celu odtworzenia pierwotnego kształtu spoin oraz miejscowe impulsowe przetapianie laserowe lica spoin naprawczych w celach dekoracyjnych.

\section{Wstęp}

Elementy zniszczonego podczas kradzieży napisu ARBEIT MACHT FREI $z$ bramy głównej byłego niemieckiego, nazistowskiego obozu Auschwitz I, zostały poddane bardzo starannym działaniom konserwatorskim

Mgr Agnieszka Żydzik-Białek, Dipl.-Rest. (FH) Margrit Bormann, mgr Andrzej Jastrzębiowski

- Państwowe Muzeum Auschwitz-Birkenau w Oświęcimiu, mgr inż. Marcin Ciepły, Mirosław Pęcherek, Marek Potrzebski - FormSerwis, Bydgoszcz, dr hab. inż. Eugeniusz Turyk, mgr inż. Tadeusz Kuzio, dr inż. Bogusław Czwórnóg - Instytut Spawalnictwa, Gliwice.

\section{Abstract}

The paper presents application of the laser welding in repair of the ARBEIT MACHT FREI inscription. It included production of the face side runs in butt joints of tubes bonding the inscription structure, repair welding of fractures in the original welds joining letters with tubes, surfacing in order to reconstruct original shape of welds as well as laser spot impulse remelting of the weld faces for decoration purposes.

realizowanym przez Sekcję Konserwatorską Państwowego Muzeum Auschwitz-Birkenau. Poszczególne elementy napisu zostały połączone z zastosowaniem technologii spawania. Istotną rolę w przygotowaniu elementów do spawania odegrało prostowanie elementów napisu przez firmę metaloplastyki artystycznej EDEX-POL w Sułkowicach. Instytut Spawalnictwa przeprowadził prace dotyczące wyboru technologii spawania naprawczego elementów napisu, spełniającej wymagania Sekcji Konserwatorskiej, oraz sprawował nadzór technologiczny przy spawaniu naprawczym elementów napisu. Spawanie elementów napisu wykonała firma FormSerwis z Bydgoszczy, spełniając wszystkie wymagania Sekcji Konserwatorskiej [1, 2] i Instytutu Spawalnictwa [3, 4]. Przebieg i wyniki tych prac przedstawiono w [5]. Niniejszy 


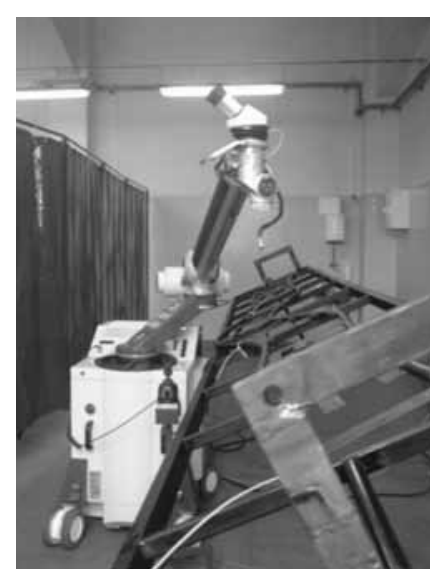

Rys. 1. Urządzenie laserowe ALM 200 na stanowisku do spawania napisu zamocowanego na stole montażowym

Fig. 1. ALM 200 laser equipment in the station for welding of the inscription fixed in the welding bench

artykuł poświęcono szczegółom zastosowania w pracach naprawczych spawania laserowego, podkreślając jego specyfikę i zalety [6].

\section{Urządzenia spawalnicze}

Stanowisko spawalnicze w pomieszczeniu Warsztatu Ślusarskiego Działu Konserwacji Muzeum firma FormSerwis wyposażyła w urządzenie do spawania metodą TIG typu Inverter-TIG-Power 1965 DC-HF-Puls prod. CEBORA oraz urządzenie ALM 200 prod. ALPHA LASER (Niemcy) przeznaczone do spawania i napawania laserowego $z$ głowicą ruchomą (rys. 1).

Urządzenie to jest wyposażone w laser impulsowy Nd:YAG o długości fali $1064 \mathrm{~nm}$, średniej mocy $200 \mathrm{~W}$ i energii impulsu $90 \mathrm{~J}$ [7]. Jest ono mobilne (wymiary 1400x730x1505 mm, masa $345 \mathrm{~kg}$ ) i umożliwia spawanie laserem w różnorodnych, trudno dostępnych miejscach. Ruch ramienia z obrotowo-wychylną głowicą laserową jest sterowany przez operatora za pomocą joysticka. Możliwości operowania tą głowicą są podobne jak przy spawaniu uchwytem TIG.

\section{Technologia spawania}

Do wykonywania złączy doczołowych rur napisu przyjęto technologię spawania warstwy przetopowej i wypełniającej metodą TIG, a następnie
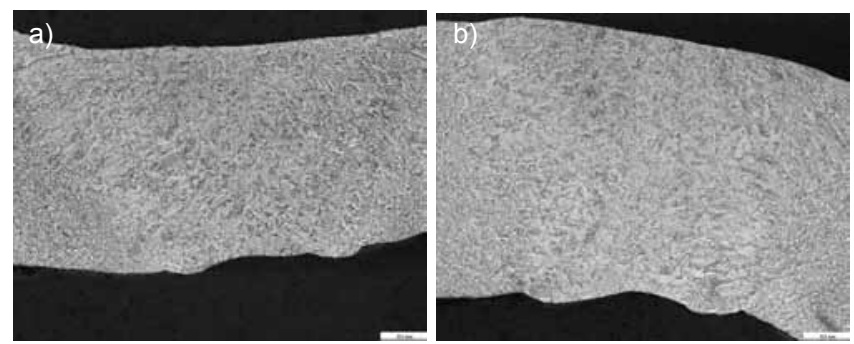

Rys. 2. Makrostruktura złącza rury wykonanego metodą TIG: a) obwodowego, b) wzdłużnego. Traw. Nital

Fig. 2. Macrostructure of TIG welded joint of a tube: a) circumferential, b) longitudinal welds. Nital etching

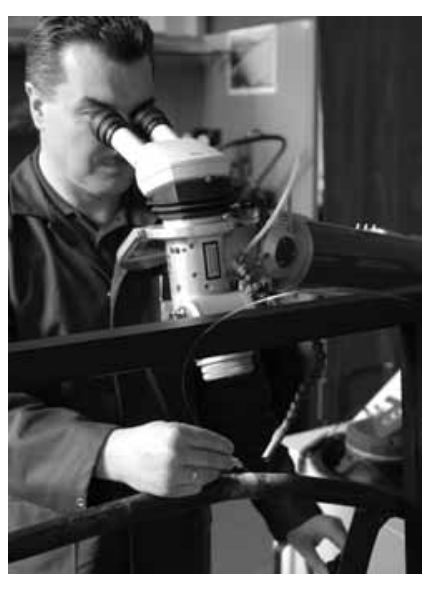

Rys. 3. Spawanie laserowe złącza doczołowego rury dolnej napisu (operator Mirosław Pęcherek)

Fig. 3. Laser welding of butt joint in lower tube of the inscription (operator Mirosław Pęcherek)

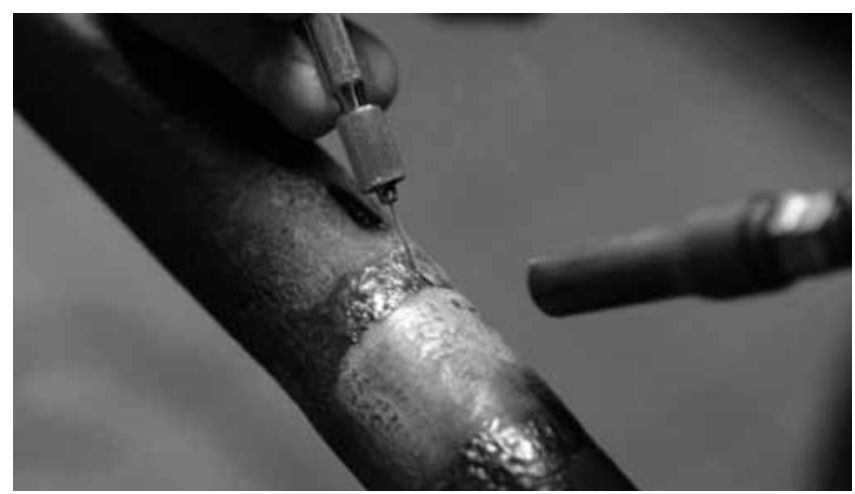

Rys. 4. Strefa spawania laserowego warstwy licowej złącza doczołowego rury napisu

Fig. 4. Laser welded zone of the face layer of the butt joint in the inscription tube

ułożenie warstwy licowej laserowo. Wyniki badań modelowych złączy próbnych rur, obejmujących kontrolę wizualną, badania metalograficzne makroskopowe i badania twardości, potwierdziły przydatność do spawania naprawczego napisu metodą TIG oraz metodą laserową wg instrukcji technologicznych spawania WPS opracowanych przez FormSerwis $\mathrm{Na}$ rysunku 2 zamieszczono zdjęcia makrostruktury złączy modelowych wykonanych przez spawacza TIG w ramach dopuszczenia do prac naprawczych. Badania wykazały poziom jakości B złączy obwodowych i złącza wzdłużnego rury, przy czym ocenie nie poddawano przesunięcia liniowego występującego w rurach celowo odkształconych przed spawaniem.

Przed spawaniem złącza górnej i dolnej rury (średnicy $33 \times 3 \mathrm{~mm}$ ) historycznego napisu zostały zukosowane na $V$, kąt ukosowania wynosił $50 \div 60^{\circ}$. Spawanie prowadzono w pozycji podolnej. Do spawania metodą TIG zastosowano pręty CastoTIG 45255W prod. Castolin Eutectic. Po spawaniu metodą TIG szlifowano nadlew wykonanej spoiny do głębokości 0,3 $\div 0,4 \mathrm{~mm}$ poniżej średnicy zewnętrznej rury i wykonywano metodą laserową warstwę licową. Do spawania laserowego stosowano drut LaserTech 45273 LA o średnicy $0,6 \mathrm{~mm}$, prod. Castolin Eutectic. Drut ten był podawany przez operatora do strefy spawania ręcznie (rys. 3 i 4). Kąt nachylenia i średnica wiązki laserowej, kąt 
a)
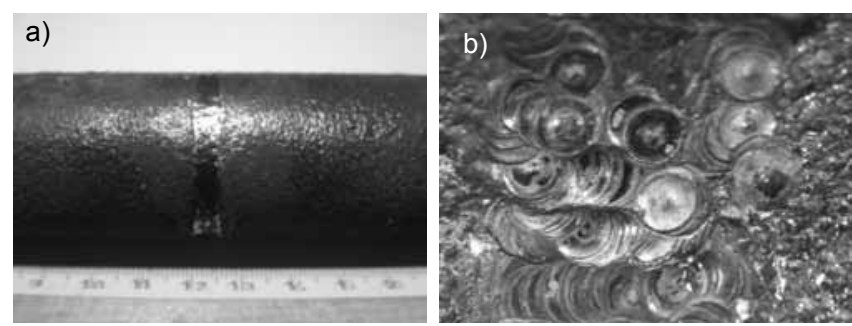

Rys. 5. Widok złącza doczołowego rur (a) i plamek dekoracyjnych wykonanych laserem na licu spoiny (b)

Fig. 5. Butt joint in tubes (a) and decoration spots made with laser in the weld face (b)

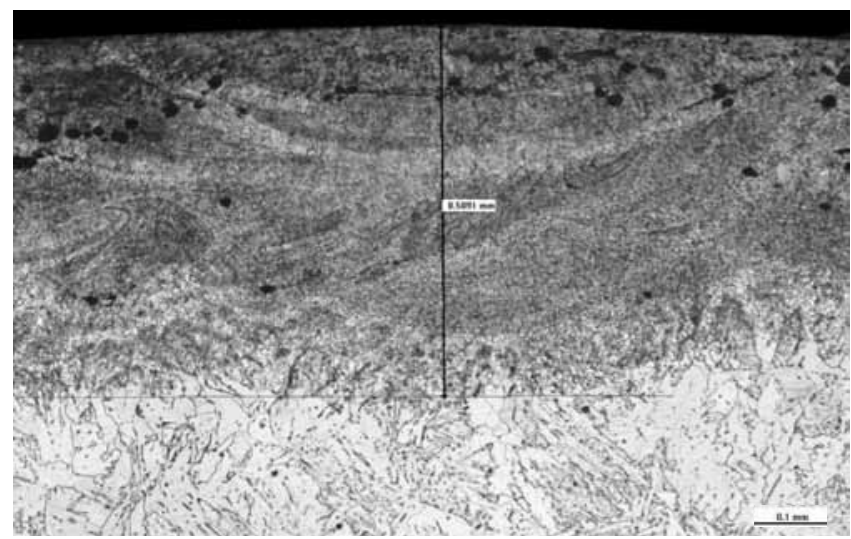

Rys. 6. Struktura strefy powierzchniowej poddanej impulsowej obróbce laserowej z zaznaczoną głębokością miejscowego wtopienia 0,5091 mm (zgład $\mathrm{nr} 5$ ). Widoczne drobne pęcherze gazowe. Traw. Nital. Pow. 200x

Fig. 6. The structure of surface layer subjected to impulse laser processing with local penetration depth of $0,5091 \mathrm{~mm}$ marked (macrosection No. 5). Visible small gas cavities. Nital etching, magn. 200x

pochylenia drutu, kierunek podawania drutu i położenie końcówki drutu względem ogniska wiązki laserowej zapewniały wymagane wtopienie i prawidłowe formowanie układanego ściegu.

Spawanie laserowe elementów napisu prowadzono z osłoną gazową argonu wysokiej czystości Argon Premier N $5.2(99,9992 \%$ Ar), prod. Air Products. Stosowano tryb spawania impulsowy, moc impulsu wynosiła $185 \mathrm{~W}$, energia impulsu $11,5 \mathrm{~J}$, a czas trwania impulsu wynosił 9,5 ms.

Próby technologiczne potwierdziły także możliwość wykonywania na licu spoin laserem impulsowym, bez dodatku spoiwa, nieregularnych dekoracyjnych plamek, maskujących charakterystyczny układ izoterm krystalizacji (rys. 5).

Wstępne próby wykonywania plamek dekoracyjnych przeprowadzono bez osłony gazowej, w celu uzyskania efektu utlenienia (zaczernienia) powierzchni. Badania metalograficzne wykazały, że głębokość wtopienia $w$ miejscach plamek nie przekracza $0,52 \mathrm{~mm}$. Stwierdzono także, że w warstwie licowej w obszarze plamek występują pęcherze gazowe (rys. 6).

W związku z tym, w celu wyeliminowania porowatości przy wykonywaniu plamek, zastosowano osłonę argonu, analogicznie jak przy spawaniu laserowym warstwy licowej.

\section{Technologia naprawcza laserowego spawania pęknięć}

Kontrola wizualna spoin napisu, wykonana po piaskowaniu, wykazała obecność krótkich pęknięć w niektórych oryginalnych spoinach. Do zaspawania tych wąskich szczelin nie są przydatne metody: TIG oraz mikroplazmowa ze względu na stosunkowo dużą szerokość układanych ściegów. Metody te nie spełniają wymagania Sekcji Konserwatorskiej dotyczącego minimalnej ingerencji w materię zabytkową napisu. Znacznie węższe ściegi uzyskuje się przy spawaniu laserowym. W związku z tym została wykonana próba spawania laserowego pęknięcia spoiny w górnym złączu spawanym litery R z rurą w wyrazie FREI (rys. 7).
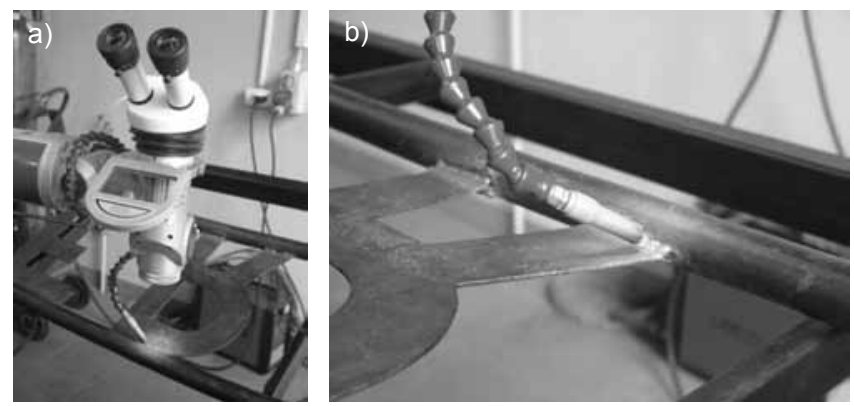

Rys. 7. Laserowe spawanie litery $R$ w wyrazie FREI: a) ustawienie głowicy laserowej, b) ustawienie dyszy doprowadzającej gaz osłonowy do strefy spawania

Fig. 7. Laser welding of the letter $R$ in the word FREl: a) laser head setting, b) the setting of a nozzle supplying shielding gas to the weIding zone

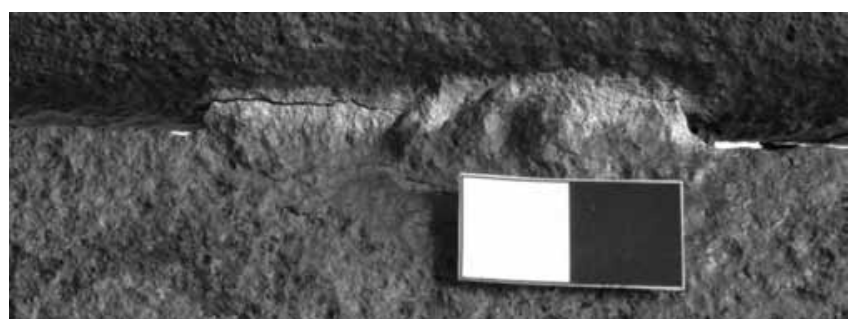

Rys. 8. Pęknięcie w górnym złączu spawanym litery $R$ z rurą w wyrazie FREI

Fig. 8. A fracture in the upper welded joint of letter $R$ and tube in the word FREI

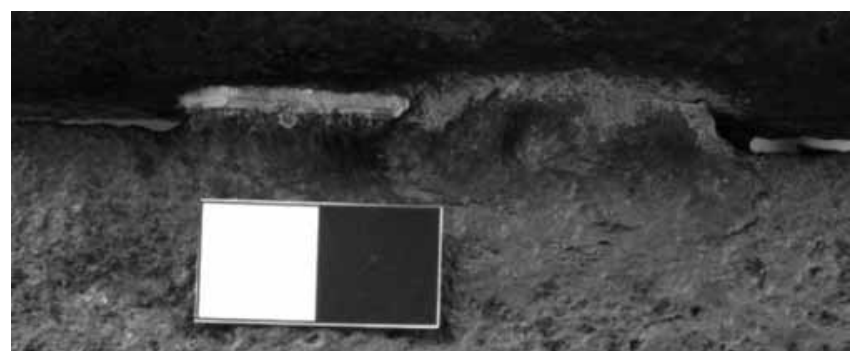

Rys. 9. Spoina laserowa w górnym złączu spawanym litery $R$ z rurą w wyrazie FREI. Widoczny układ zachodzących na siebie dwóch ściegów lica spoiny

Fig. 9. Laser weld in the upper welded joint of letter $R$ and tube in the word FREI. Visible two overlap runs of the weld face 
Widok pęknięcia przed spawaniem oraz po spawaniu przedstawiono na rysunkach 8 i 9 . Kontrola wizualna wykazała, że spoina laserowa jest prawie niewidoczna, więc uzyskany został równocześnie efekt dekoracyjny (rys. 9). W związku z tym uzgodniono, że inne nieduże pęknięcia, wyszczególnione w opracowaniu [4], które nie będą naprawiane metoda TIG, zostaną zaspawane laserowo, aby zachować ich dotychczasowy stan [8].

\section{Odtworzenie pierwotnego kształtu spoin}

Wykorzystując możliwości napawania laserowego, podjęto próbę odtworzenia pierwotnego kształtu spoin wg fotografii napisu, wykonanych przez Sekcję Konserwatorską w 2006 r. Dotyczyło to:

- dolnej przedniej spoiny w złączu litery $T$ w wyrazie ARBEIT,

- górnej i dolnej w złączach litery I w wyrazie FREI,

- dolnej w złączu litery R w wyrazie FREI.

\section{Podsumowanie}

Spawanie laserowe zostało zastosowane w pracach konserwatorskich dotyczących naprawy historycznego napisu ARBEIT MACHT FREI, z bramy głównej byłego niemieckiego, nazistowskiego obozu Auschwitz I, przy:

- wykonywaniu warstwy licowej złączy rury dolnej i górnej napisu,

- spawaniu naprawczym pęknięć w oryginalnych spoinach łączących litery $z$ rurami napisu,

- napawaniu w celu odtworzenia pierwotnego kształtu spoin według archiwalnych fotografii.

W przypadku złączy rurowych oraz pozostałych złączy, gdzie zgodnie z wymaganiami Sekcji Konserwatorskiej wskazane było pokrycie ich powierzchni

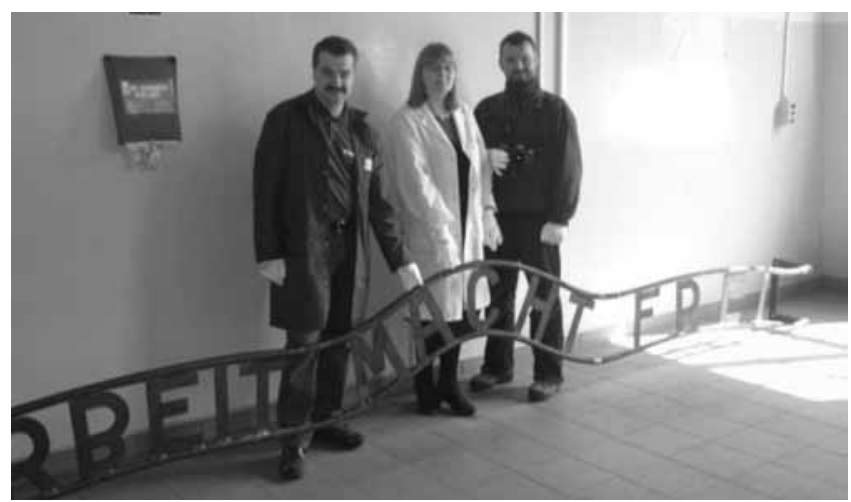

Rys. 10. Historyczny napis po zakończeniu prac spawalniczych Od lewej stoją: Mirosław Pęcherek, Agnieszka Żydzik-Białek i Andrzej Jastrzębiowski

Fig. 10. Original inscription after termination of the welding works. Standing from the left: Mirosław Pęcherek, Agnieszka Żydzik-Białek and Andrzej Jastrzębiowski.

Kontrola wizualna wykonanych w ten sposób spoin nie wykazała w nich niezgodności spawalniczych typu pęknięcia oraz pory gazowe. Kształt odtworzonych spoin został zaakceptowany przez Sekcję Konserwatorską.

\section{Literatura}

[1] Napis ARBEIT MACHT FREI z bramy głównej byłego obozu AUSCHWITZ I. Nr inw. A-43. Opracowanie Sekcji Konserwatorskiej Państwowego Muzeum Auschwitz-Birkenau w Oświęcimiu, 2010.

[2] Żydzik-Białek A., Jastrzębiowski A.: Program prac konserwatorskich. Napis ARBEIT MACHT FREI z bramy głównej byłego obozu AUSCHWITZ I. Nr inw. A-43. Sekcja Konserwatorska Państwowego Muzeum Auschwitz-Birkenau, 2010.

[3] Wykonanie badań dotyczących wyboru technologii spawania elementów napisu ARBEIT MACHT FREI z bramy głównej byłego obozu Auschwitz I. Orzeczenie nr ZT/294/10. Instytut Spawalnictwa, Gliwice, 2011.

[4] Nadzór technologiczny przy spawaniu naprawczym elementów napisu ARBEIT MACHT FREI z bramy głównej byłego

plamkami dekoracyjnymi, zastosowane zostało miejscowe przetapianie laserowe, w celu naniesienia na licu złączy spawanych nieregularnie rozmieszczonych plamek. Impulsowa obróbka laserowa zapewniła spełnienie wymagania, aby połączenia fragmentów napisu były nie tylko trwałe, lecz także jak najmniej widoczne.

Jakość spawanych złączy napisu spełnia wymagania Sekcji Konserwatorskiej Państwowego Muzeum Auschwitz-Birkenau pod względem kształtu, wymiarów i wyglądu powierzchni. Scalony napis (rys. 10) został przekazany do dalszych prac konserwatorskich, przed jego umieszczeniem na planowanej nowej wystawie głównej Muzeum. obozu Auschwitz I. Orzeczenie nr ZT/289/11. Instytut Spawalnictwa, Gliwice, 2011.

[5] Turyk E., Żydzik-Białek A., Bormann M., Jastrzębiowski A., Kościelniak M., Kuzio T, Czwórnóg B.: Spawanie naprawcze elementów napisu ARBEIT MACHT FREI z głównej bramy wejściowej byłego niemieckiego, nazistowskiego obozu Auschwitz I. Biuletyn Instytutu Spawalnictwa, nr 6/2011, s. 42-48.

[6] Banasik M.: Spajanie ze spoiwem w postaci drutu laserami różnych typów. Biuletyn Instytutu Spawalnictwa, Gliwice, 5/2011, s. 32-35.

[7] Systemy do spawania laserowego. www.alphalaser.de.

[8] Mapowanie spawów obrazujące ich stan zachowania. Sekcja Konserwatorska Państwowego Muzeum Auschwitz-Birkenau, Oświęcim, 2011. 